\title{
Experimental Study and Application of Inorganic Solidified Foam Filling Material for Coal Mines
}

\author{
Hu Wen, ${ }^{1,2,3}$ Duo Zhang, ${ }^{1,2,3}$ Zhijin Yu, ${ }^{1,2,3}$ Xuezhao Zheng, ${ }^{1,2,3}$ \\ Shixing Fan, ${ }^{1,2,3}$ and Bin Laiwang ${ }^{4}$ \\ ${ }^{1}$ School of Safety Science and Engineering, Xian University of Science and Technology, Xian, Shaanxi 710054, China \\ ${ }^{2}$ Key Laboratory of Mine and Disaster Prevention and Control of Ministry of Education, Xian University of Science and Technology, \\ Xian, Shaanxi 710054, China \\ ${ }^{3}$ Xian Research Center National Mine Rescue, Xian, Shaanxi 710054, China \\ ${ }^{4}$ Doctoral Program, Graduate School of Engineering Science and Technology, National Yunlin University of Science and Technology, \\ 123 University Rd., Sec. 3, Douliou, Yunlin 64002, Taiwan
}

Correspondence should be addressed to Duo Zhang; b201512041@stu.xust.edu.cn

Received 25 April 2017; Revised 23 June 2017; Accepted 10 July 2017; Published 10 August 2017

Academic Editor: Prinya Chindaprasirt

Copyright (C) $2017 \mathrm{Hu}$ Wen et al. This is an open access article distributed under the Creative Commons Attribution License, which permits unrestricted use, distribution, and reproduction in any medium, provided the original work is properly cited.

\begin{abstract}
Spontaneous combustion of residual coal in a gob due to air leakage poses a major risk to mining safety. Building an airtight wall is an effective measure for controlling air leakage. A new type of inorganic solidified foam-filled material was developed and its physical and chemical properties were analyzed experimentally. The compressive strength of this material increased with the amount of sulphoaluminate cement. With an increasing water-cement ratio, the initial setting time was gradually extended while the final setting time firstly shortened and then extended. The change in compressive strength had the opposite tendency. Additionally, as the foam expansion ratio increased, the solidification time tended to decrease but the compressive strength remained approximately constant. With an increase in foam production, the solidification time increased and the compressive strength decreased exponentially. The results can be used to determine the optimal material ratios of inorganic solidified foamfilled material for coal mines, and filling technology for an airtight wall was designed. A field application of the new material demonstrated that it seals crossheadings tightly, leaves no fissures, suppresses air leakage to the gob, and narrows the width of the spontaneous combustion and heat accumulation zone.
\end{abstract}

\section{Introduction}

As a major source of energy, coal accounts for $76 \%$ of primary energy consumption in China and its dominant position in the energy structure cannot be replaced over the long term $[1,2]$. The safety of coal mines is thus of critical importance to China's socioeconomic development $[3,4]$.

In many modern coal mines in China, the mining roadway is excavated by double tunneling with a continuous miner, resulting in a dense distribution of crossheadings between the two tunnels (with adjacent crossheadings being separated by about $50 \mathrm{~m}$ ). During mining, the crossheadings should be sealed to reduce air leakage to the gob and further to prevent the spontaneous combustion of coal and gas explosions [5]. In 2012, a gas explosion accident occurred at the Number 53 crossheading in the gob of working face 22113 in the Cuner colliery, Shenfu-Dongsheng coalfield, Shaanxi Province, China. A detailed investigation concluded that this accident was caused by a loose airtight wall in the crossheading. Because air entered the gob through the fissures of the airtight wall, the residual coal oxidized spontaneously and there was eventually a gas explosion.

In the 1990s, the United States, Germany, Australia, and other countries with advanced coal mining techniques began to study and apply various airtight filling materials [6-10]. In contrast, China is a late comer to research on filling and plugging materials. Chinese workers still use materials like wood, loess, cement grouting [11], and fly ash grouting in coal mines. Recent years have witnessed the development and application of new filling materials, including gel materials, 
fly ash composite colloid [12,13], paste backfilling [14], thickened mortar [15], rigid polyurethane foam [16], Marithan, and Igloneige [17]. However, all these filling materials have disadvantages. Loess and cement slurry, for example, cannot be directly connected to the roof and have relatively low compressive strength. As a new type of excellent cooling and inerting material, gel materials readily crack after dehydration, resulting in poor compressive strength. Organic filling materials like Marithan are expensive and release toxic gases at high temperatures although they are effective in stopping leaks.

Foam has received much attention because of its low density, low thermal conductivity, low permeability, high expansibility, and high strength [18]. The former Soviet Union, United States, northern European countries, and Japan have developed foam cement and successfully applied the cement in construction and oil development [19-22]. Kearsley and Wainwright explored the relationship between the compressive strength and thermal conductivity of foamed concrete and analyzed the effect of the fly ash content on compressive strength [23-26]. Jambor and Luping probed the effect of the pore structure on the strength of foam concrete [27, 28]. Nambiar and Ramamurthy [29] and Kearsley and Wainwright[25] studied the gas pore characteristics of foamed concrete and the effect of porosity on the strength of foamed concrete, respectively. Although many researchers have gone to great effort to investigate foam cement, they have seldom researched filling materials to be used in an underground coal mine in an effort to improve the performance and reduce the cost of the materials. China University of Mining and Technology (Beijing) developed a foamed cement and used the filling to stop leaks [30, 31]. However, the product is not suitable for extensive use because it relies on a special type of cement, which is difficult to prepare and costly.

The aims of the present paper are to develop a highquality, low-cost inorganic solidified foam-filled material adopting raw materials, such as ordinary Portland cement, fly ash, gelling agent, water, foaming agent, and water reducer, employing a physical mixing method for foaming.

\section{Experimental Materials and Methods}

2.1. Experimental Materials. The following samples were used in experiments:

(1) Ordinary Portland cement (Yulin Shanshui Cement Plant, Shaanxi Province, China)

(2) Sulphoaluminate cement (SC) with apparent density of $3.21 \mathrm{~kg} / \mathrm{m}^{3}$

(3) Fly ash (Daliuta Thermal Power Plant, Shenfu-Dongsheng Coal Mining Area, Shaanxi Province, China)

(4) Lignosulfonate water reducer (Shaanxi QinFen Building Material Co., Ltd., Shaanxi Province, China).

Lauryl amidopropyl betaine $\left(\mathrm{C}_{20} \mathrm{H}_{40} \mathrm{~N}_{2} \mathrm{O}_{3}\right)$ and potassium monoalkyl phosphate $\left(\mathrm{C}_{12} \mathrm{H}_{25} \mathrm{OPO}_{3} \mathrm{~K}_{2}\right)$ were used as activators of the foaming agent and were mixed at a ratio of $7: 3$. Triethanolamine $\left(\mathrm{C}_{6} \mathrm{H}_{15} \mathrm{NO}_{3}\right)$ and oleic acid $\left(\mathrm{C}_{18} \mathrm{H}_{34} \mathrm{O}_{2}\right)$ were used as foam stabilizers and were mixed at a ratio of $1: 1$. The foaming agent and foam stabilizers were mixed at a ratio of $1: 1$. The foam was prepared following steps described in the literature [32].

2.2. Experimental Instruments. The experimental instruments included a compressed-air foam generator [32], LQA30001 electronic balance (Ruian Ante Weighing Equipment Co., Ltd., Zhejiang Province, China), NJ-160 cement mixer (Shangyu Zheyi Machinery Manufacturing Co., Ltd., Zhejiang Province, China), Vicat Apparatus (Shandong Taoyin E-commerce Co., Ltd., Shandong Province, China), and YA-2000 microcontrolled pressure testing machine (Shenyang Baote Instrument Co., Ltd., Liaoning Province, China).

\subsection{Experimental Methods}

2.3.1. Determination of the Gel Time. The following procedure was used in experiments.

(1) The slurry of inorganic gelled foam was poured into a circular die (having an upper inner diameter of $65 \mathrm{~mm}$, lower inner diameter of $75 \mathrm{~mm}$, and height of $40 \mathrm{~mm}$ ), and the time was recorded.

(2) The initial setting test needle was replaced with the final setting test needle. The test needle was released when the material was about to enter the phase of initial setting.

(3) The time when the test needle reached a level $4 \pm$ $1 \mathrm{~mm}$ above the bottom plate was recorded; this was the initial setting time of the material.

(4) The die was turned through $180^{\circ}$ and the height of the test needle was adjusted so that the lower surface of the needle was at the same level as the surface of the material inside the circular die. The test needle was released when the material was about to enter the phase of final setting. The time when the test needle submerged into the test piece by $0.5 \mathrm{~mm}$ was recorded; this was the final setting time of the material.

2.3.2. Determination of Compressive Strength. Cubic specimens of inorganic foam material having dimensions of $100 \mathrm{~mm} \times 100 \mathrm{~mm} \times 100 \mathrm{~mm}$ were made and dried in an oven (at $105^{\circ} \mathrm{C}$ for 4 hours). A microcontrolled pressure testing machine was used to apply continuous and uniform pressure to the cubic specimens until the blocks were damaged. The load at that moment was the maximum failure load $F$. The compressive strength can be calculated as [33]

$$
f=\frac{F}{A},
$$

where $f$ is the compressive strength of the test piece (MPa) accurate to $0.01 \mathrm{MPa}, F$ is the maximum failure load $(\mathrm{N})$, and $A$ is the compression area of the test piece $\left(\mathrm{mm}^{2}\right)$. 


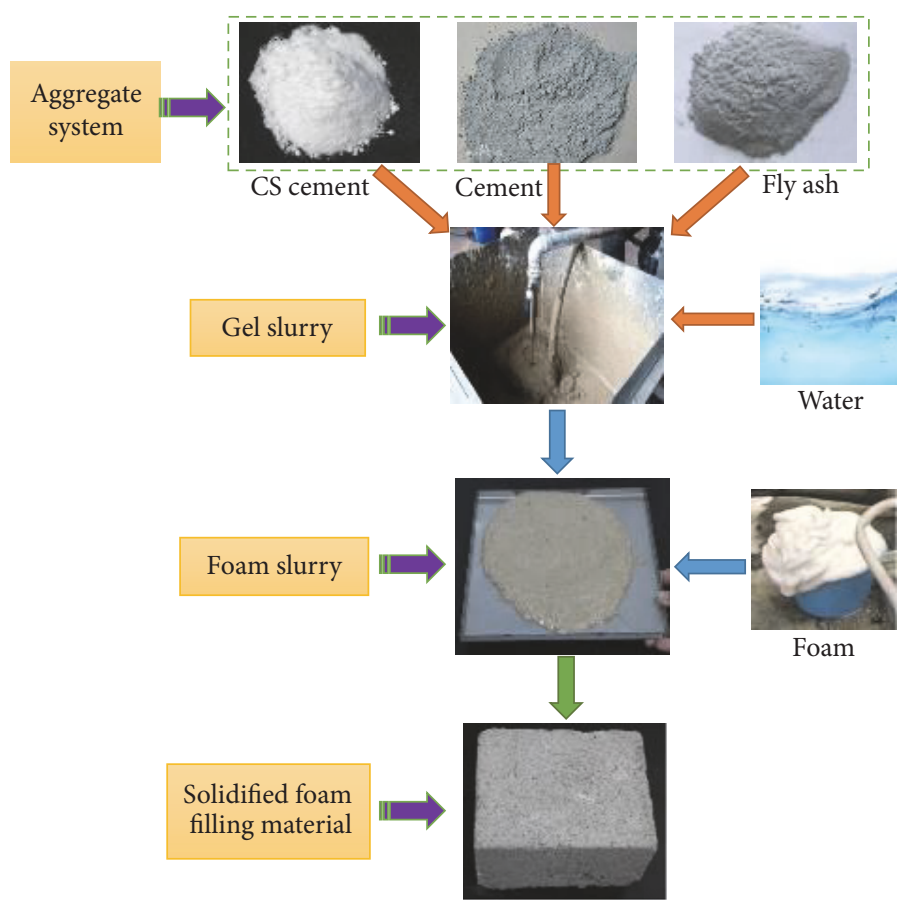

FIgURE 1: Preparation of the filling material.

TABLE 1: Chemical composition of ordinary Portland cement (\%).

\begin{tabular}{lcccccccc}
\hline $\mathrm{CaO}$ & $\mathrm{SiO}_{2}$ & $\mathrm{Al}_{2} \mathrm{O}_{3}$ & $\mathrm{Fe}_{2} \mathrm{O}_{3}$ & $\mathrm{SO}_{3}$ & $\mathrm{MgO}$ & $\mathrm{TiO}_{2}$ & $\mathrm{~K}_{2} \mathrm{O}$ & $\mathrm{Na}_{2} \mathrm{O}$ \\
\hline 64.28 & 20.47 & 6.57 & 2.79 & 1.17 & 2.31 & 0.91 & 0.84 & 0.66 \\
\hline
\end{tabular}

TABle 2: Physical parameters of ordinary Portland cement.

\begin{tabular}{lccccc}
\hline $\begin{array}{l}\text { Fineness }(0.08 \mathrm{~mm} \text {, residue on } \\
\text { square hole sieve) }\end{array}$ & $\begin{array}{c}\text { Apparent density } \\
\left(\mathrm{kg} / \mathrm{m}^{3}\right)\end{array}$ & $\begin{array}{c}\text { Initial setting time } \\
(\mathrm{min})\end{array}$ & $\begin{array}{c}\text { Final setting time } \\
(\mathrm{min})\end{array}$ & \multicolumn{2}{c}{$\begin{array}{c}\text { Compressive strength }(\mathrm{MPa}) \\
1 \mathrm{~d}\end{array}$} \\
\hline $8 \%$ & 3.06 & 139 & 375 & 12.8 \\
\hline
\end{tabular}

TABLE 3: Chemical composition of sulphoaluminate cement (\%).

\begin{tabular}{lcccccc}
\hline $\mathrm{CaO}$ & $\mathrm{SiO}_{2}$ & $\mathrm{Al}_{2} \mathrm{O}_{3}$ & $\mathrm{Fe}_{2} \mathrm{O}_{3}$ & $\mathrm{SO}_{3}$ & $\mathrm{MgO}$ & $\mathrm{TiO}_{2}$ \\
\hline 42.44 & 12.46 & 30.58 & 2.54 & 9.52 & 0.64 & 1.82 \\
\hline
\end{tabular}

2.3.3. Material Preparation. The test procedure was as follows.

(1) SC, ordinary Portland cement, and fly ash were mixed in certain proportions, to produce an aggregate system.

(2) The aggregate system and water were mixed in certain proportions, to produce a gel slurry.

(3) The gel slurry and foam were evenly mixed in certain proportions, to produce a foam slurry.

(4) The foam slurry was poured into a mold, and the solidified material was the foam filling material.

The process of preparing inorganic solidified foam filling material is shown in Figure 1.

\section{Experimental Results and Analysis}

3.1. Material Analysis. Physical properties and chemical compositions of the ordinary Portland cement, SC, and fly ash are listed in Tables 1-6.

3.2. Effect of SC Cement on Material Properties. To explore how the dosage of SC cement affects the inorganic solidified foam, experiments were designed as shown in Table 7 . We adjusted the dosage of SC cement and measured the material gel time and compressive strength, as presented in Figure 2.

Figure 2 reveals that, as the dosage of SC cement increased, both the initial and final setting times shortened and the compressive strengths for different ages gradually increased. After the dosage exceeded 30\%, the solidification time decreased at a much slower pace. The compressive strength of the filling material was much higher on the 28th 
TABLE 4: Physical parameters of sulphoaluminate cement.

\begin{tabular}{lcccc}
\hline Apparent density $\left(\mathrm{kg} / \mathrm{m}^{3}\right)$ & Initial setting time $(\mathrm{min})$ & Final setting time $(\mathrm{min})$ & \multicolumn{2}{c}{ Compressive strength (MPa) } \\
& 10 & 30 & $1 \mathrm{~d}$ & 37.5 \\
\hline 3.21 & & & 51 \\
\hline
\end{tabular}

TABLE 5: Chemical composition of fly ash (\%).

\begin{tabular}{ccccccccc}
\hline $\mathrm{CaO}$ & $\mathrm{SiO}_{2}$ & $\mathrm{Al}_{2} \mathrm{O}_{3}$ & $\mathrm{Fe}_{2} \mathrm{O}_{3}$ & $\mathrm{SO}_{3}$ & $\mathrm{MgO}$ & $\mathrm{TiO}_{2}$ & $\mathrm{~K}_{2} \mathrm{O}$ & $\mathrm{Na}_{2} \mathrm{O}$ \\
\hline 12.24 & 49.02 & 22.81 & 6.79 & 1.67 & 2.49 & 0.97 & 2.59 & 1.42 \\
\hline
\end{tabular}

TABLE 6: Physical parameters of fly ash.

Soundness $(<1 \mathrm{~mm}$, this was

defined as the increased distance Fineness $(<0.045 \mathrm{~mm}$, after boiling by Le-Chatelier $\%)$

Loss on ignition (\%) Water content ratio (\%)

Water content (\%) method)

\begin{tabular}{llllll}
\hline 4.5 & 33.4 & 8.3 & 102 & 0.8 \\
\hline
\end{tabular}

TABLE 7: Experimental design of the sulphoaluminate cement content.

\begin{tabular}{|c|c|c|c|c|c|c|c|}
\hline \multirow{2}{*}{ Sequence } & \multicolumn{3}{|c|}{ Aggregate system } & \multirow{2}{*}{$\begin{array}{l}\text { Water-cement } \\
\text { ratio }(\%)\end{array}$} & \multicolumn{2}{|c|}{ Foam } & \multirow{2}{*}{$\begin{array}{l}\text { Gel slurry- } \\
\text { foam ratio }\end{array}$} \\
\hline & Cement (\%) & SC (\%) & Fly ash (\%) & & Foaming multiple & Dosage $(\mathrm{mL})$ & \\
\hline 1 & 100 & 0 & 0 & 50 & 10 & 200 & 1 \\
\hline 2 & 95 & 5 & 0 & 50 & 10 & 200 & 1 \\
\hline 3 & 90 & 10 & 0 & 50 & 10 & 200 & 1 \\
\hline 4 & 85 & 15 & 0 & 50 & 10 & 200 & 1 \\
\hline 5 & 80 & 20 & 0 & 50 & 10 & 200 & 1 \\
\hline 6 & 75 & 25 & 0 & 50 & 10 & 200 & 1 \\
\hline 7 & 70 & 30 & 0 & 50 & 10 & 200 & 1 \\
\hline 8 & 65 & 35 & 0 & 50 & 10 & 200 & 1 \\
\hline 9 & 60 & 40 & 0 & 50 & 10 & 200 & 1 \\
\hline 10 & 55 & 45 & 0 & 50 & 10 & 200 & 1 \\
\hline 11 & 50 & 50 & 0 & 50 & 10 & 200 & 1 \\
\hline
\end{tabular}

Note. The gelling agent contained $0.1 \%$ water reducer; the water-cement ratio is the mass ratio of water to aggregate system; the gel-foam ratio is the ratio of the volume of the gel slurry to the volume of the foam.

day than on the first day. After the dosage exceeded $40 \%$, the compressive strength on the 28 th day slightly fell. The above phenomena are explained as follows. In the early stage, as the dosage increased, the solidification time shortened but the compressive strength gradually increased because the gas pores in the solidified foam cement were intact. After the dosage exceeded $30 \%$, the solidification time reduced at a much slower place. As the dosage continued to rise, the SC cement would encase the ordinary Portland cement, which hindered the hydration of the ordinary Portland cement and thereby lessened the compressive strength of the material. As a result, the optimal dosage of SC cement was between $30 \%$ and $40 \%$.

3.3. Effect of Fly Ash on Material Properties. Previous research has found that fly ash has little effect on the strength of a material, except when the dosage is excessive $[22,34]$. To study how the dosage of fly ash affects the inorganic solidified foam, an experiment was designed as shown in Table 8.
The solidification time and compressive strength of the material at different dosages of fly ash are illustrated in Figure 3. When the dosage of fly ash fell between $0 \%$ and $20 \%$, both the initial and final setting times lengthened slightly while the compressive strengths on the 1st and 28th days decreased slightly. When the fly ash content was between $20 \%$ and $30 \%$, the initial setting time increased appreciably and the final setting time first shortened and then lengthened. The compressive strengths on the 1st and 28th days gradually decreased while the compressive strength on the 90th day increased with the dosage of fly ash. The above results are explained as follows. The glassy fly ash served as a framework among the cement particles and increased the density of the material. Fly ash reacted with cement to form strong covalent bonds. The secondary hydration reaction among $\mathrm{SiO}_{2}, \mathrm{Al}_{2} \mathrm{O}_{3}$, and $\mathrm{Fe}_{2} \mathrm{O}_{3}$ in the fly ash and $\mathrm{Ca}(\mathrm{OH})_{2}$, a product of cement hydration, produced C-S-H and C-A-H. The products filled up the cementitious material, refined the preliminary size, and altered the interface structure, thereby improving the 
TABLE 8: Experimental design of the fly ash content.

\begin{tabular}{|c|c|c|c|c|c|c|c|}
\hline \multirow{2}{*}{ Sequence } & \multicolumn{3}{|c|}{ Aggregate system } & \multirow{2}{*}{$\begin{array}{l}\text { Water-cement } \\
\text { ratio }(\%)\end{array}$} & \multicolumn{2}{|c|}{ Foam } & \multirow{2}{*}{$\begin{array}{l}\text { Gel slurry- } \\
\text { foam ratio }\end{array}$} \\
\hline & Cement (\%) & SC (\%) & Fly ash (\%) & & Foaming multiple & Dosage $(\mathrm{mL})$ & \\
\hline 1 & 60 & 40 & 0 & 50 & 10 & 200 & 1 \\
\hline 2 & 57 & 38 & 5 & 50 & 10 & 200 & 1 \\
\hline 3 & 54 & 36 & 10 & 50 & 10 & 200 & 1 \\
\hline 4 & 51 & 34 & 15 & 50 & 10 & 200 & 1 \\
\hline 5 & 48 & 32 & 20 & 50 & 10 & 200 & 1 \\
\hline 6 & 45 & 30 & 25 & 50 & 10 & 200 & 1 \\
\hline 7 & 42 & 28 & 30 & 50 & 10 & 200 & 1 \\
\hline
\end{tabular}

Note. The gelling agent contained $0.1 \%$ water reducer.

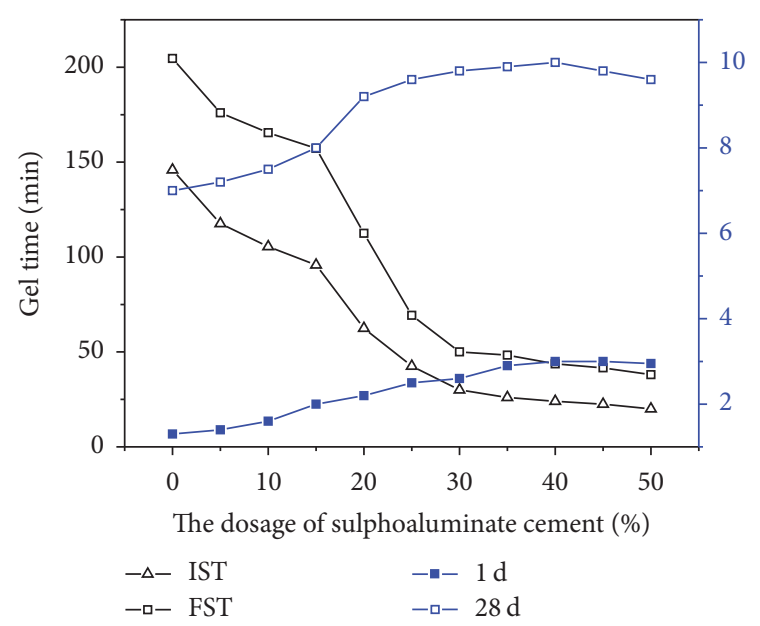

(a)

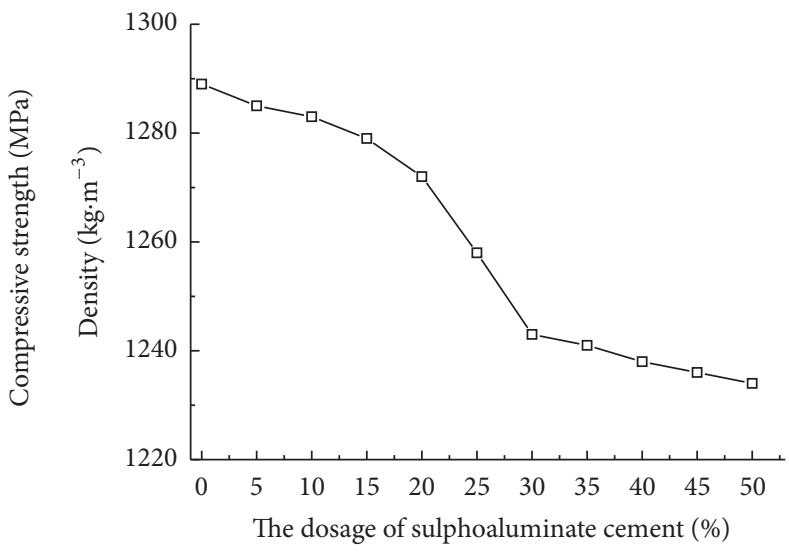

(b)

FIGURE 2: Effect of the dosage of sulphoaluminate cement on the filling material. Note. IST: initial setting time; FST: final setting time.

compressive strength $[35,36]$. Because of the low activity of fly ash, the secondary hydration reaction did not occur unless the cement was hydrated to release enough $\mathrm{Ca}(\mathrm{OH})_{2}$ to increase the environmental alkalinity and turn the fly ash from inert to active. The compressive strength on the 28th day therefore lagged the actual status and does not accurately reflect the pozzolanic activity of fly ash [37].

\subsection{Effect of the Water-Cement Ratio on Material Properties.} To study how the water-cement ratio affects the inorganic solidified foam, an experiment was designed as shown in Table 9.

The material properties were tested at different water-cement ratios. Because the water reducer affected the water consumption of the material, we carried out three groups of comparative tests at water reducer contents of $0 \%$, $0.1 \%$, and $0.2 \%$.

Figure 4 illustrates the effects of the water-cement ratio and water reducer on the solidification time. As the water-cement ratio rose, the initial setting times of all materials gradually lengthened. The final setting times of all materials firstly shortened and then lengthened. The material with no water reducer had a longer initial setting time than the materials for which the water reducer was added. After the water-cement ratio exceeded 0.4 , the material with no water reducer had a longer final setting time than the materials with the water reducer. The above results are explained as follows. When the water-cement ratio was relatively low, the material slurry was highly viscous and readily reached its initial setting state. There was thus insufficient water for the hydration reaction, which lengthened the final setting time. When the water-cement ratio was excessively high, the water in the material slurry diluted the $\mathrm{SiO}_{2}, \mathrm{Al}_{2} \mathrm{O}_{3}$, and $\mathrm{Ca}(\mathrm{OH})_{2}$ necessary for the secondary hydration reaction, which also lengthened the final setting time.

Figure 5 presents results for the materials with different amounts of water reducer. As the water-cement ratio rose, the compressive strengths on the 1st and 28th days both firstly increased and then decreased. After the water-cement ratio surpassed 0.45 , the material with no water reducer had a lower compressive strength than materials of the same age with water reducer. When the dosage of water reducer was $0.1 \%$ or $0.2 \%$, there was no appreciable difference in the compressive strengths of materials of the same age. The above results are explained as follows. In the mixing process, both the cement and foam absorbed water. Owing to the better hydrophily and water absorbability of cement, the foam had to adhere to the surface of cement particles to absorb the little 
TABLE 9: Experimental design of water-cement ratio.

\begin{tabular}{|c|c|c|c|c|c|c|c|}
\hline \multirow{2}{*}{ Sequence } & \multicolumn{3}{|c|}{ Aggregate system } & \multirow{2}{*}{$\begin{array}{l}\text { Water-cement } \\
\text { ratio }(\%)\end{array}$} & \multicolumn{2}{|c|}{ Foam } & \multirow{2}{*}{$\begin{array}{l}\text { Gel slurry- } \\
\text { foam ratio }\end{array}$} \\
\hline & Cement (\%) & SC (\%) & Fly ash (\%) & & Foaming multiple & Dosage $(\mathrm{mL})$ & \\
\hline 1 & 48 & 32 & 20 & 25 & 10 & 200 & 1 \\
\hline 2 & 48 & 32 & 20 & 35 & 10 & 200 & 1 \\
\hline 3 & 48 & 32 & 20 & 45 & 10 & 200 & 1 \\
\hline 4 & 48 & 32 & 20 & 55 & 10 & 200 & 1 \\
\hline 5 & 48 & 32 & 20 & 65 & 10 & 200 & 1 \\
\hline 6 & 48 & 32 & 20 & 75 & 10 & 200 & 1 \\
\hline 7 & 48 & 32 & 20 & 85 & 10 & 200 & 1 \\
\hline
\end{tabular}

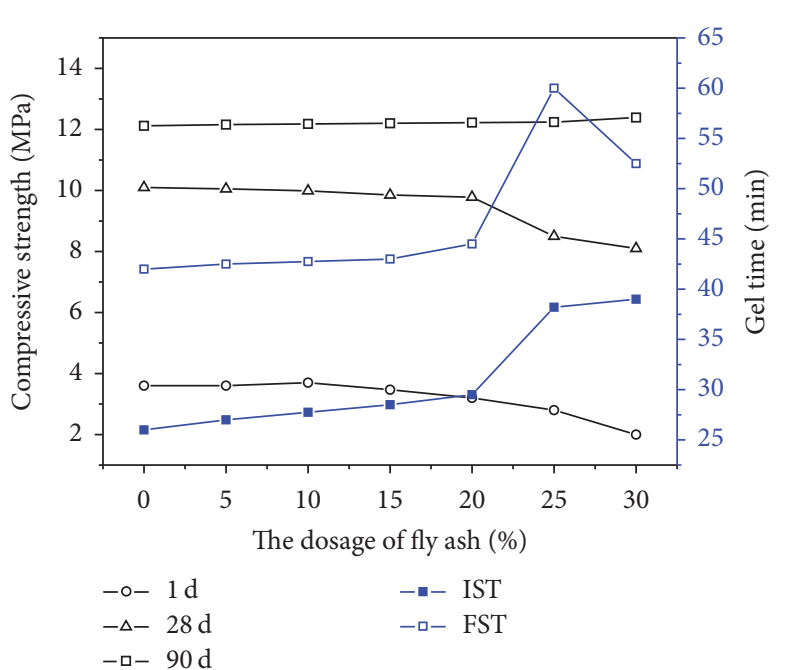

(a)

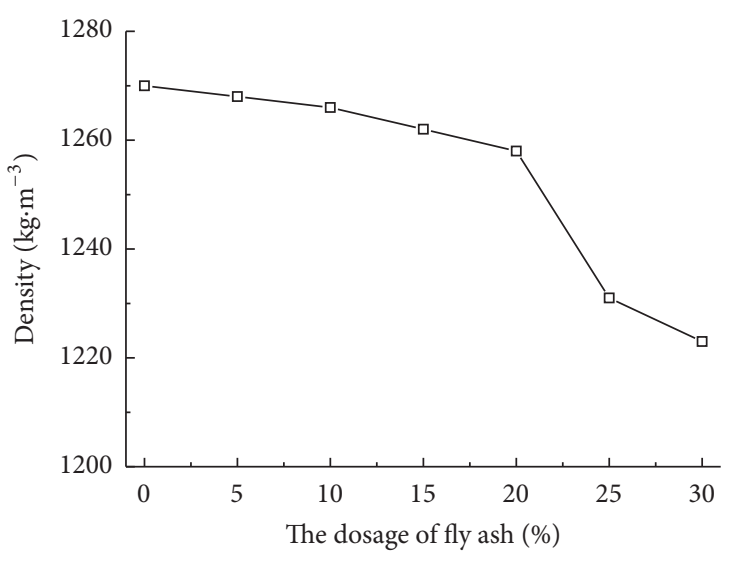

(b)

FIGURE 3: Effect of the dosage of fly ash on the filling material.

amount of water. In this process, bubbles burst under surface tension as the convex outer surfaces of bubbles were in contact with concave cement particles. The cement particles had a layer of hydrophobic groups on their surfaces. When other bubbles came into contact with cement particles, they burst as hydrophilic groups encountered hydrophobic groups. As a result, the low water-cement ratio affected the hydration and solidification time of cement and reduced the compressive strength of the material. When the water-cement ratio was greater than 0.55 , the foam mixed into the slurry because of the superior fluidity of the latter. Meanwhile, excessive water reduced the stability of the foam, undermined the pore structure of the material, and lowered the material strength. The optimal water-cement ratio thus fell between 0.4 and 0.5 , and the optimal dosage of water reducer was $0.1 \%$.

3.5. Effect of Foam on a Material. To study the effect of the foam on an inorganic solidified foam material, an experiment was designed as shown in Tables 10 and 11.

3.5.1. Effect of the Foam Expansion Ratio on the Material. Figure 6 illustrates the effect of the foam expansion ratio on the solidification time and compressive strength. It is seen that both the initial and final setting times decreased as the expansion ratio rose. The expansion ratio had little effect on the compressive strength of materials on the 1st and 28th days. When the expansion ratio was 15 , the material surpassed all others in terms of compressive strengths on the 1st and 28th days, which were 3.15 and 10.34 MPa. Both values were above $1 \mathrm{MPa}$, the threshold strength required to support overlying rock $[38,39]$.

3.5.2. Effect of the Foam Dosage on the Material. Figure 7 presents the effect of the foam dosage on the solidification time and compressive strength. It is seen that the solidification time gradually lengthened as the dosage of foam gradually increased, and the compressive strengths on the 1st and 28th days both dropped dramatically with an increase in the foam dosage. The above results are explained as follows. As the dosage of foam increased, the dry density of the material gradually fell and the porosity grew [25]. The increasing number of closed pores in the material then reduced the compressive strength. The material therefore performed best when the foam had the same volume as the gel slurry.

3.6. Scanning Electron Microscopy. We mixed raw materials in the following proportions. The ratio of ordinary Portland 
TABLE 10: Effect of expansion ratio on the material.

\begin{tabular}{|c|c|c|c|c|c|c|c|}
\hline \multirow{2}{*}{ Sequence } & \multicolumn{3}{|c|}{ Aggregate system } & \multirow{2}{*}{$\begin{array}{l}\text { Water-cement } \\
\text { ratio }(\%)\end{array}$} & \multicolumn{2}{|c|}{ Foam } & \multirow{2}{*}{$\begin{array}{l}\text { Gel slurry- } \\
\text { foam ratio }\end{array}$} \\
\hline & Cement (\%) & SC (\%) & Fly ash (\%) & & Foaming multiple & Dosage $(\mathrm{mL})$ & \\
\hline 1 & 48 & 32 & 20 & 45 & 5.2 & 200 & 1 \\
\hline 2 & 48 & 32 & 20 & 45 & 8.1 & 200 & 1 \\
\hline 3 & 48 & 32 & 20 & 45 & 11.7 & 200 & 1 \\
\hline 4 & 48 & 32 & 20 & 45 & 15.1 & 200 & 1 \\
\hline 5 & 48 & 32 & 20 & 45 & 18.1 & 200 & 1 \\
\hline
\end{tabular}

TABLE 11: Effect of the dosage of foam on the material.

\begin{tabular}{lccccccc}
\hline Sequence & Cement (\%) & $\begin{array}{c}\text { Aggregate system } \\
\text { SC (\%) }\end{array}$ & Fly ash (\%) & $\begin{array}{c}\text { Water-cement } \\
\text { ratio (\%) }\end{array}$ & $\begin{array}{c}\text { Foam } \\
\text { Foaming multiple }\end{array}$ & $\begin{array}{c}\text { Gel slurry- } \\
\text { foam ratio }\end{array}$ \\
\hline 1 & 48 & 32 & 20 & 45 & 15 & 1 & 200 \\
2 & 48 & 32 & 20 & 45 & 15 & 400 & 0.5 \\
3 & 48 & 32 & 20 & 45 & 15 & 0.25 \\
4 & 48 & 32 & 20 & 45 & 15 & 1500 & 0.2 \\
5 & 48 & 32 & 20 & 45 & 15 & 0.1 \\
\hline
\end{tabular}

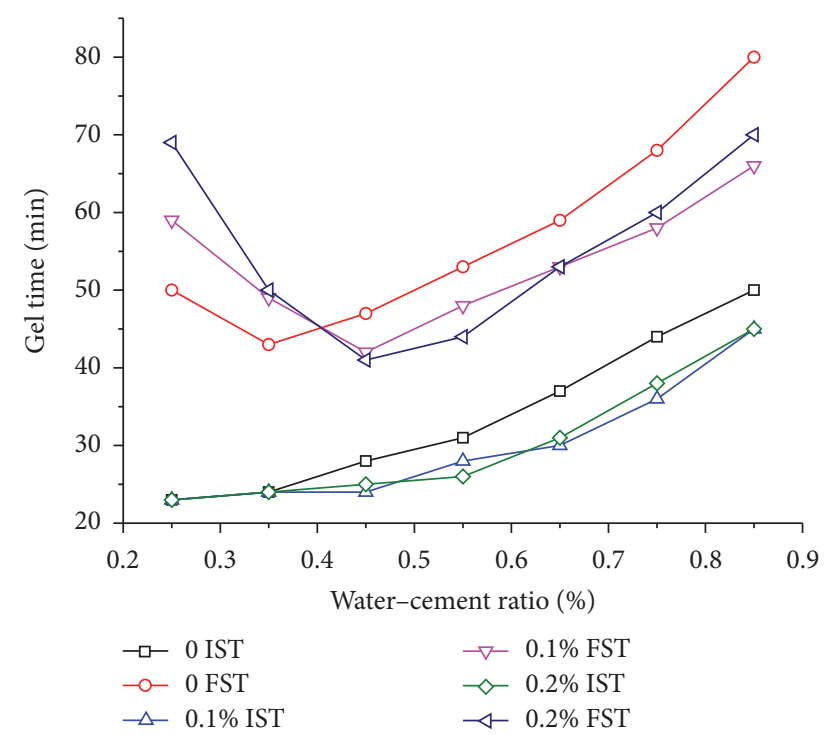

FIGURE 4: Effect of water-cement ratio and water reducer on gelling time.

cement to SC to fly ash in the aggregate system was $0.48: 0.32: 0.2$; the water-cement ratio was 0.45 ; the water reducer content was $0.1 \%$; the expansion ratio was 15 ; and there were equal volumes of foam and gelling slurry. We conducted scanning electron microscopy (SEM) after mixing the raw materials. Figures 8 and 9 show SEM images of the inorganic solidified foam filling material at different ages (1st and 28th days).

Figure 8 shows that the fly ash and spherical cement particles were wrapped up by reticular hydration structures on the first day. However, the shapes of fly ash and cement particles were still distinguishable, and the pores were filled with reticular structures. Meanwhile, the reticular structure on the 28th day was bonded with fly ash and cement particles such that only a small amount of fly ash and few spherical cement particles were still visible.

Figure 9 shows the pore structure of the filling material at 60 -fold magnification on the 28 th day. The pores produced by the foaming agent were evenly distributed in the material, indicating that the strength of the foam filling material mainly depended on the pore structure and the bonding interface. The pore features were well suited to stopping leaks as most were smaller than $1 \mathrm{~mm}$.

\section{Engineering Applications}

In 2014, the CO content on working face 31403 of the Halagou coal mine, Shengfu Dongsheng Coalfield, reached 1273 ppm. Examination and analysis revealed that the airtight wall of the Number 56 crossheading on the inlet side was not tightly closed and the surrounding coal body had cracked, resulting in spontaneous combustion of residual coal in the gob. We therefore performed an industrial test at the Halagou coal mine by sealing 20 crossheadings on the inlet side on working face 31405. The best way of detecting the effect of the airtight wall was to record the oxygen concentration in the gob. Using an XK-VI coal spontaneous combustion experiment bench, we obtained the minimum oxygen concentration for the spontaneous combustion of coal on working face 31405 , which stands at $7.82 \%$.

4.1. Dimensions of the Crossheading. Figure 10 is a sketch map of the crossheading, with a height of $4 \mathrm{~m}$ and width of $5.6 \mathrm{~m}$. The crossheading was packed with $2 \mathrm{~m}$ of loess in the lower part and filled with $56.0 \mathrm{~m}^{3}$ of inorganic gelled foam cement in the upper part.

4.2. Material Ratios. The material ratios of the inorganic gelling material are as follows. The ratio of ordinary Portland cement to SC cement to fly ash in the aggregate system was 

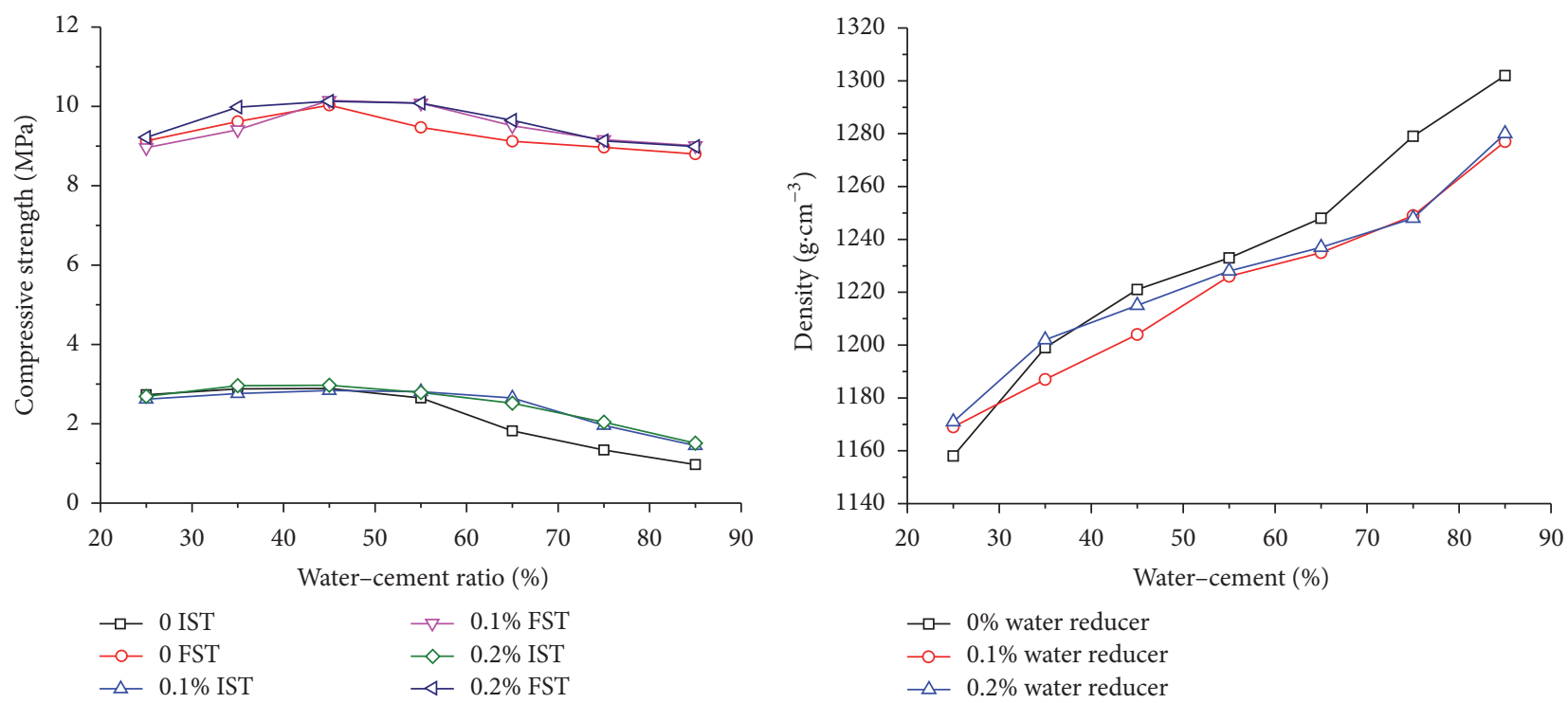

(a)

(b)

FIGURE 5: Effect of water-cement ratio and water reducer on compressive strength.

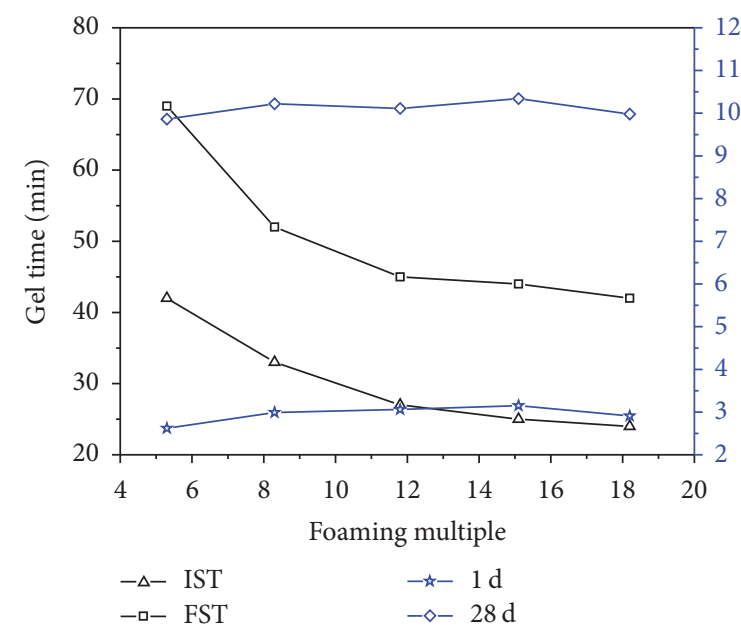

(a)

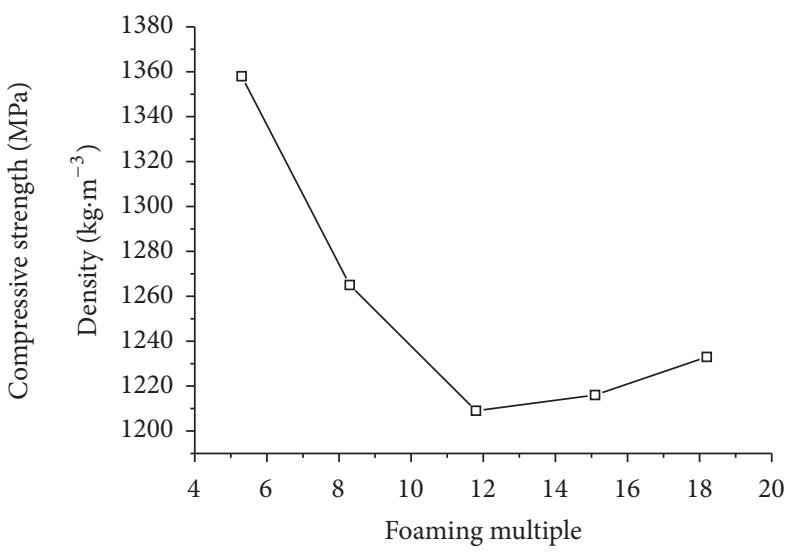

(b)

FIGURE 6: Effect of expansion ratio on the material.

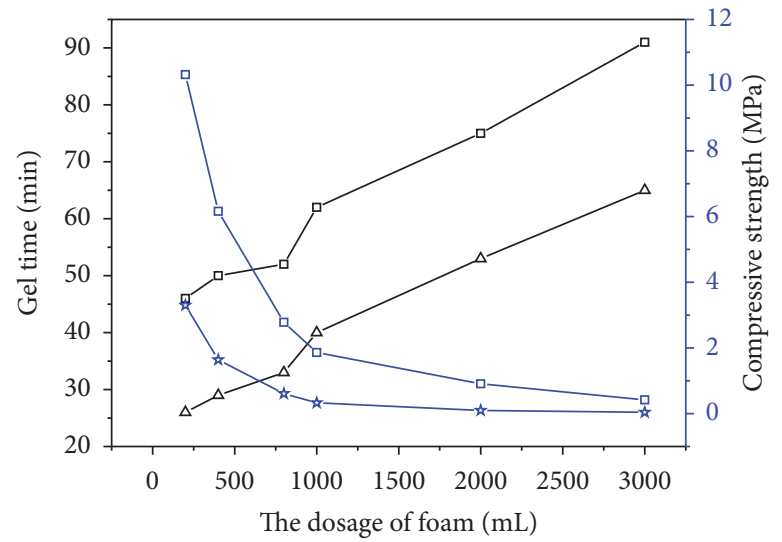

$$
-\Delta-\text { IST } \quad-\nless-1 \mathrm{~d}
$$

(a)

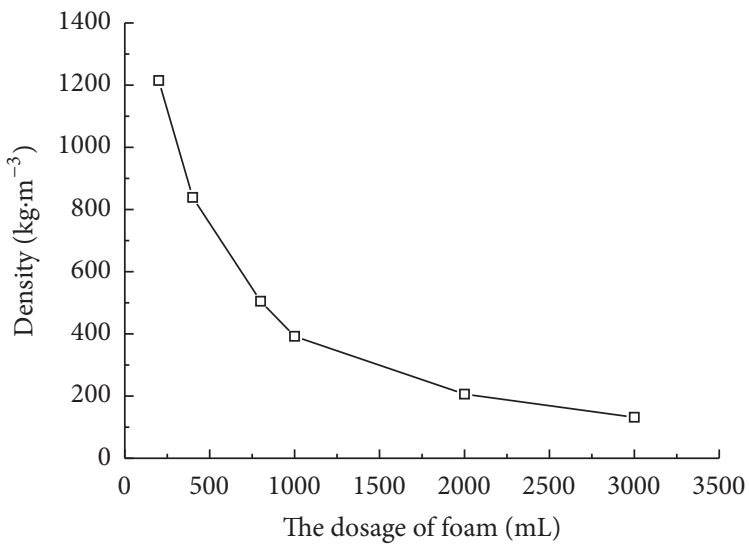

(b)

FIGURE 7: Effect of the dosage from foam on the material. 


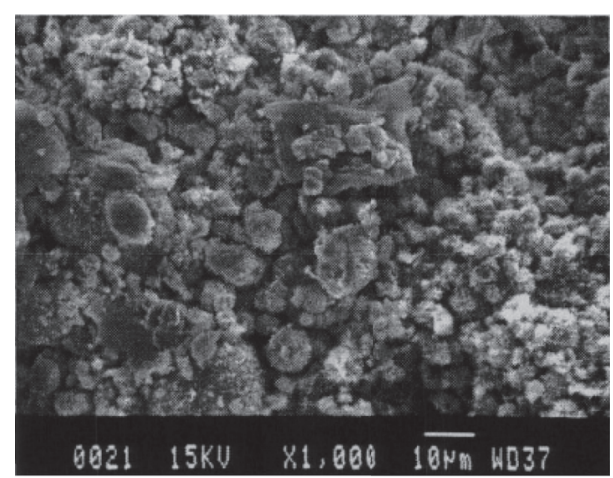

(a) $1 \mathrm{~d}$ (1,000 times)

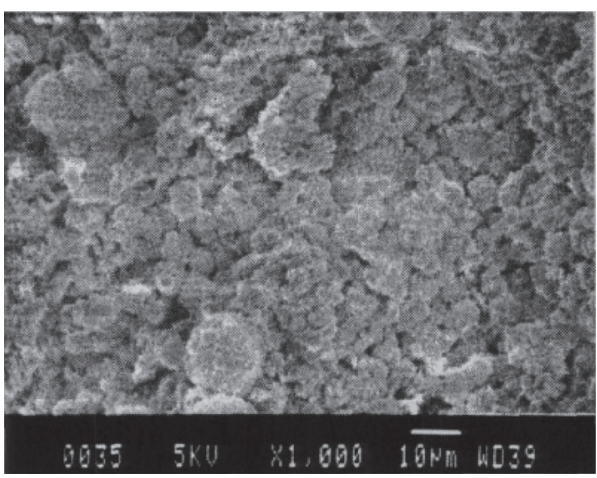

(c) $28 \mathrm{~d}(1,000$ times $)$

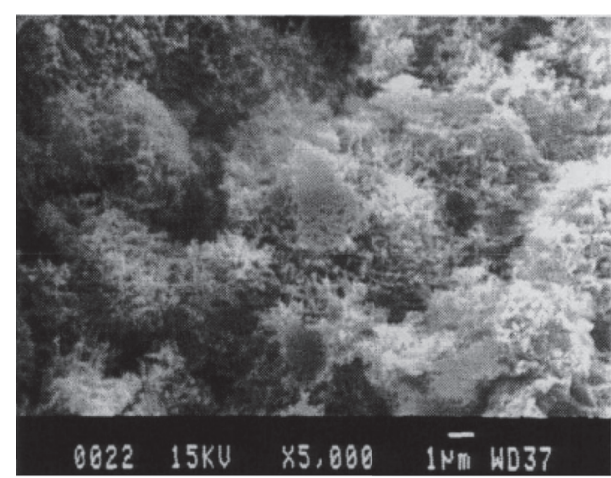

(b) $1 \mathrm{~d}$ (5,000 times)

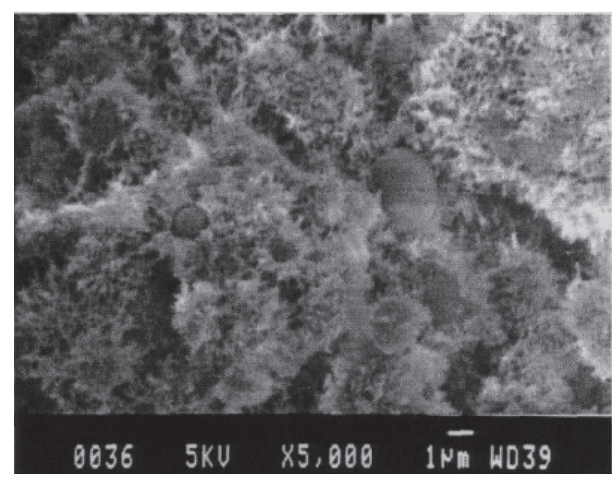

(d) $28 \mathrm{~d}$ (5,000 times)

FIGURE 8: SEM scan grams on materials at different curing ages.
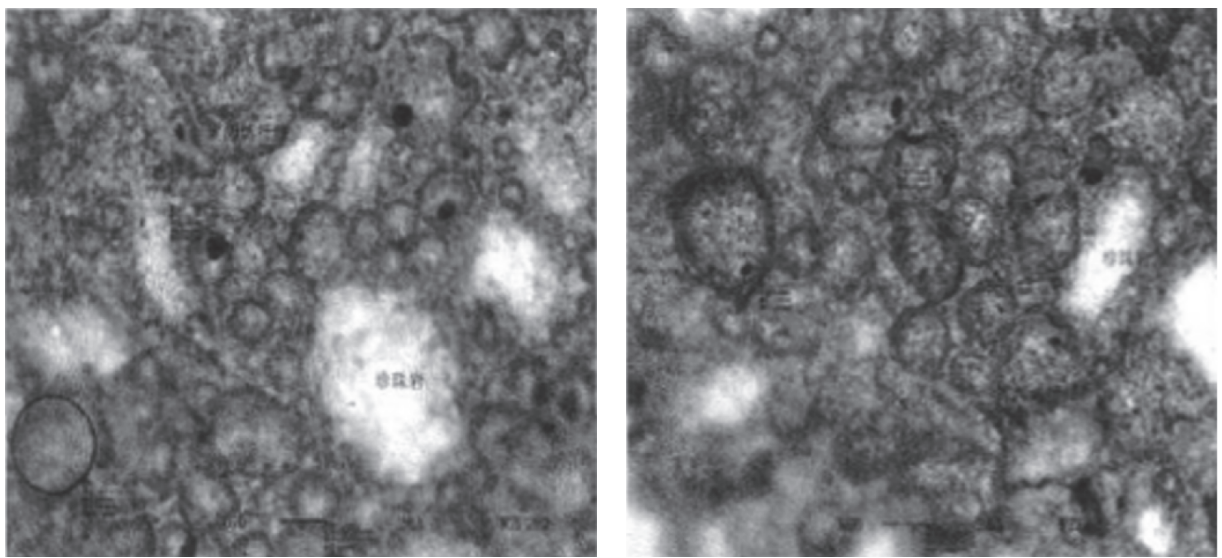

FIGURE 9: Pore structure of the filling material magnified by 60 times.

$0.48: 0.32: 0.2$; the water-cement ratio was 0.45 ; the water reducer content was $0.1 \%$; the expansion ratio was 15 ; and there were equal volumes of foam and gelling slurry.

4.3. Grouting Equipment. On the basis of the performance of the filling material, we developed a special grouting machine, as shown in Figure 11. SC, fly ash, foam, and other raw materials were mixed in the ZMJ-F-type grout making machine and stirred into a foam slurry of a certain concentration. The slurry was pumped to seal the crossheading, and the slurry solidified after a period of time. The flow rate of the foam slurry pump was $16 \mathrm{~m}^{3} / \mathrm{h}$ when the pressure was $0.6 \mathrm{MPa}$.

4.4. Filling Effect. Figure 12 shows how the external brick wall was removed to observe the filling effect after filling for $24 \mathrm{~h}$. We found that the inorganic gelling foam cement had solidified; the inorganic gelling foam cement has wellknown advantages, such as strength, airtightness, and being soundproof.

Figure 13 compares oxygen concentrations. After filling the 20 crossheadings with inorganic solidified gelling foam 


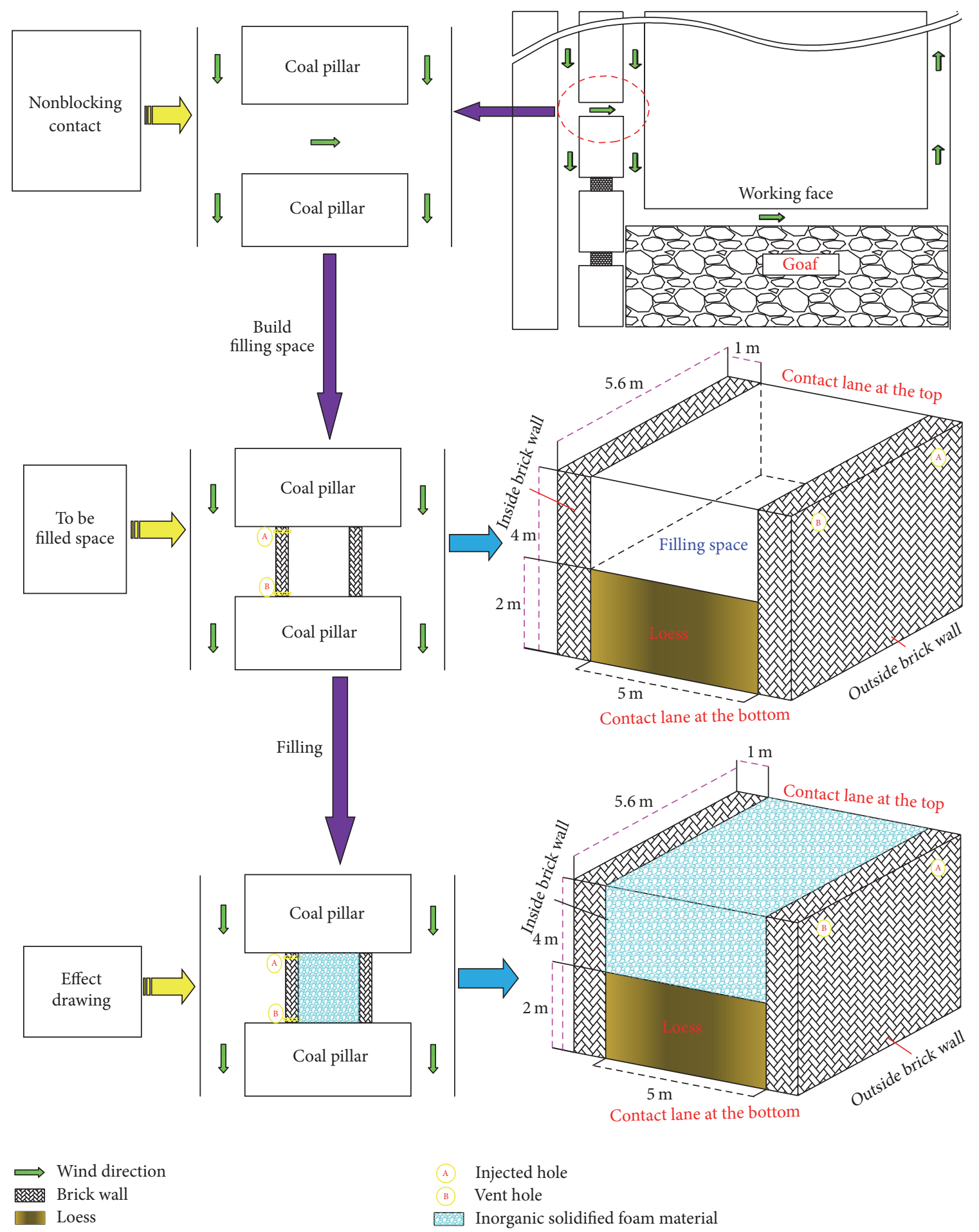

FIGURE 10: Sketch map of the grouting, filling, and sealing of the crossheading.

cement, we observed the oxygen concentration on the inlet side of the gob and compared the results with the oxygen concentration when loess was used as the filling material. After filling with foam cement material, the oxygen concentration at a point $\mathrm{W}$ that was $119.6 \mathrm{~m}$ from the working surface was $7.82 \%$. In comparison, when loess was used to fill the crossheading, the same oxygen concentration appeared at a point $\mathrm{Q}$ that was $233.8 \mathrm{~m}$ from the working surface. The distance between points $\mathrm{W}$ and $\mathrm{Q}$ was $114.2 \mathrm{~m}$. This means that the inorganic foam cement filling material controlled effectively air leakage from the crossheadings to the gob and narrowed the width of the spontaneous combustion and 


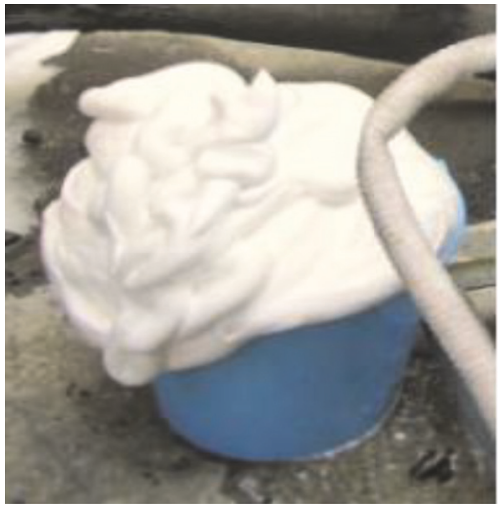

(a)

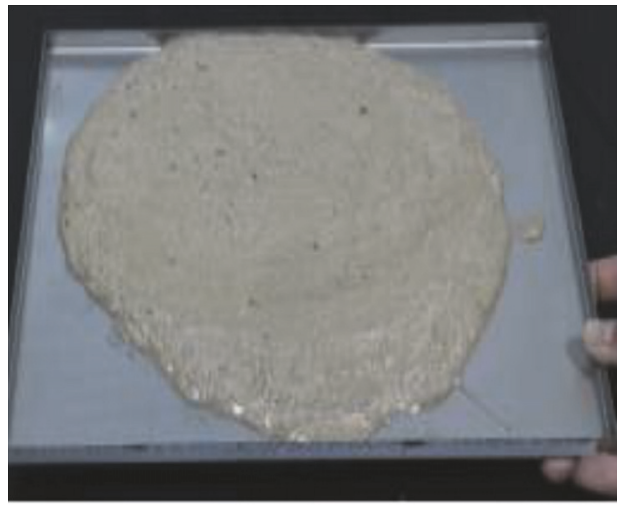

(b)

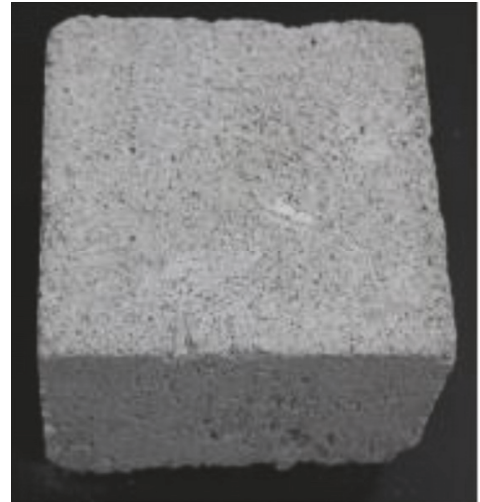

(c)

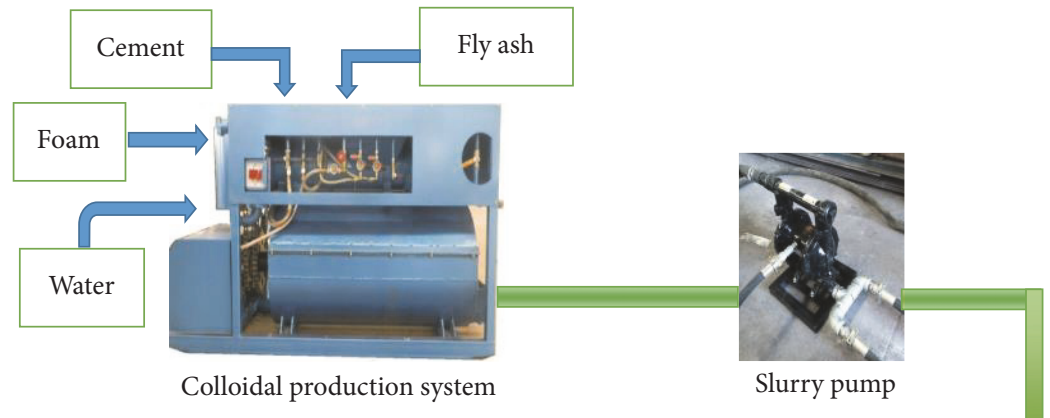

Colloidal production system

Slurry pump

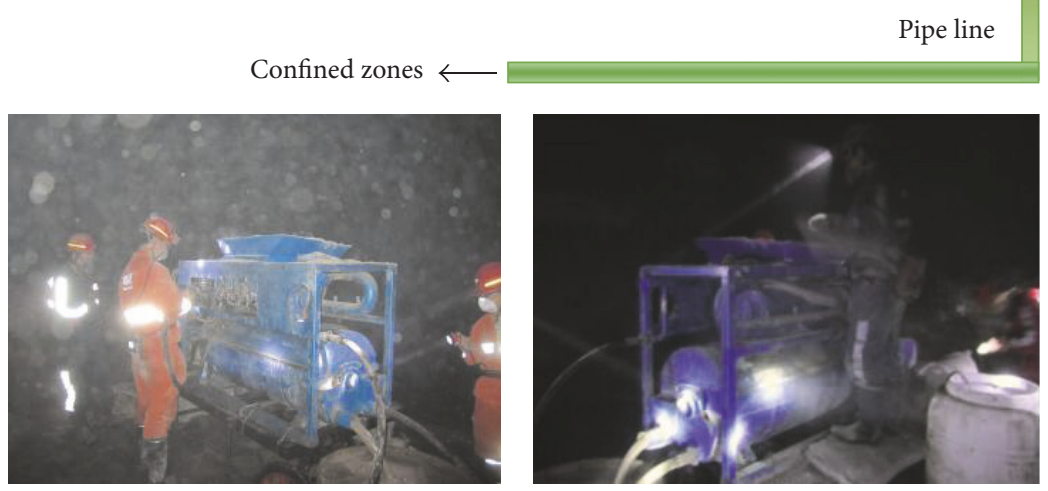

(d)

FIGURE 11: ZMJ-F grouting system: (a) foam, (b) foam slurry, (c) solidified filling material, and (d) inorganic foam filling equipment, including foam slurry production machine, transfer pump, and control system.

heat accumulation zone. Foam cement can therefore play an important role in preventing the spontaneous combustion of residual coal in the gob.

\section{Conclusions}

We conducted experiments to develop a type of inorganic solidified foam filling material for sealing crossheadings in coal mines and analyzed the effects of the dosage of SC, dosage of fly ash, water-cement ratio, expansion ratio, and foam dosage on the filling material.
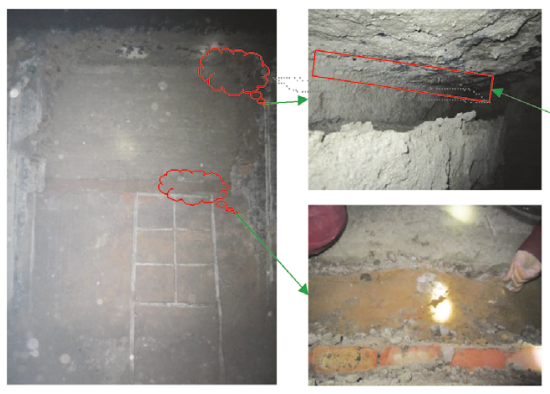

\section{Compact} seamless

Figure 12: The filling effect on mine. 


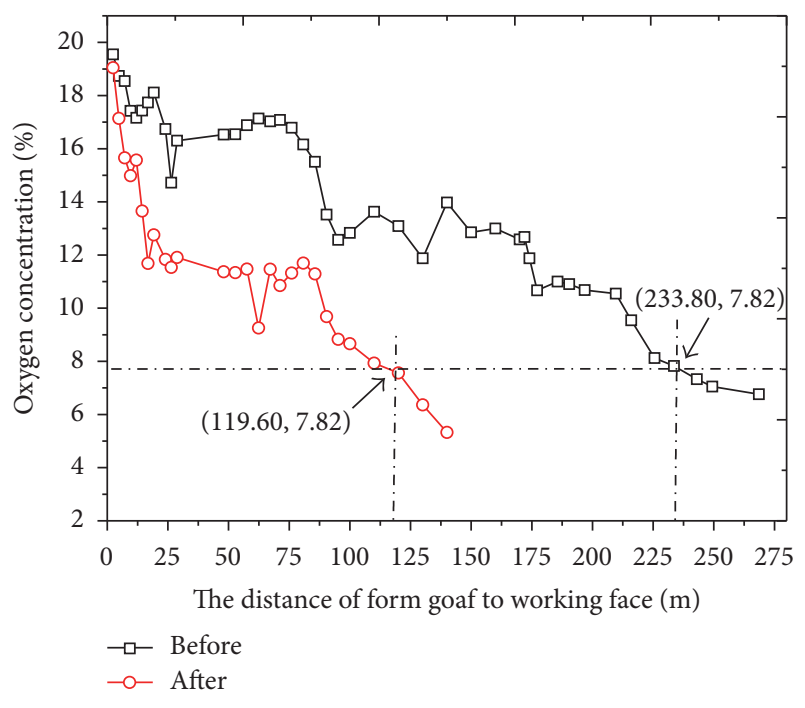

Figure 13: Comparison of oxygen concentrations. After: the oxygen concentration of the goaf after the crossheading was filled up with gelling foam cement material; before: the oxygen concentration of the goaf after the crossheading was filled up with loess.

The experimental results show that the solidification time shortened and the compressive strength grew with an increase in the content of SC. The fly ash dosage had little effect on the properties of the material if it was less than $20 \%$, but the solidification time substantially lengthened if the dosage was greater than $20 \%$. The compressive strength of the material on the 1st and 28th days decreased with an increase in the fly ash dosage. As the water-cement ratio increased, the initial setting time gradually lengthened. The final setting time shortened and then lengthened, and the compressive strength increased before decreasing. The solidification time shortened as the expansion ratio increased. However, the compressive strength did not vary after inorganic solidified foam filling material was added. With an increase in foam production, the solidification time increased and the compressive strength decreased exponentially.

On the basis of the experimental results, the best inorganic solidified foam filling material had a ratio of cement to SC to fly ash in the aggregate system of $0.48: 0.32: 0.20$; a water-cement ratio of 0.45 ; a water reducer content of $0.10 \%$; an expansion ratio of 15; and equal volumes of foam and gelling slurry.

We designed a special grouting machine to apply the filling material. The machine was air driven and easy to operate and relocate.

The field application demonstrated that the inorganic solidified foam filling material can seal crossheadings tightly and control the oxygen concentration in a gob effectively. As a kind of industrial waste, fly ash is readily available from thermal power plants in coal production regions. The proposed filling material therefore has broad application prospects owing to its low cost and suitability for large-area filling and plugging.

\section{Conflicts of Interest}

The authors declare that there are no conflicts of interest regarding the publication of this paper.

\section{Acknowledgments}

The present work was supported by the National Natural Science Foundation of China (Grants nos. U1361129 and 51504186) and China Postdoctoral Science Foundation (Program 2016-M-592820).

\section{References}

[1] S. Dale, Statistical Review of World Energy, London, England, 2015.

[2] The State Council of the People's Republic of China, "Medium and Long-term Development Plan for Energy (2004-2020), Beijing, China," 2004.

[3] L. Lang and Z. Fu-bao, "A comprehensive hazard evaluation system for spontaneous combustion of coal in underground mining," International Journal of Coal Geology, vol. 82, no. 1-2, pp. 27-36, 2010.

[4] S. Wang, K. Luo, X. Wang, and Y. Sun, "Estimate of sulfur, arsenic, mercury, fluorine emissions due to spontaneous combustion of coal gangue: an important part of chinese emission inventories," Environmental Pollution, vol. 209, pp. 107-113, 2015.

[5] H. B. Sahu, S. S. Mahapatra, and D. C. Panigrahi, "An empirical approach for classification of coal seams with respect to the spontaneous heating susceptibility of Indian coals," International Journal of Coal Geology, vol. 80, no. 3-4, pp. 175-180, 2009.

[6] S. Xue, B. Dickson, and J. Wu, "Application of 222Rn technique to locate subsurface coal heatings in Australian coal mines," International Journal of Coal Geology, vol. 74, no. 2, pp. 139-144, 2008.

[7] O. I. Ogunsola and R. J. Mikula, "A study of spontaneous combustion characteristics of Nigerian coals," Fuel, vol. 70, no. 2, pp. 258-261, 1991.

[8] C. Angle and N. Berkowitz, "Distribution of oxygen forms in Alberta low rank coals," Fuel, vol. 70, no. 7, pp. 891-896, 1991.

[9] J. C. Jones, "Steady behaviour of long duration in the spontaneous heating of a bituminous coal," Journal of Fire Sciences, vol. 14, no. 2, pp. 159-166, 1996.

[10] W. Bichler and L. Simon, "Phenolic resin foam for the sealing of loose hanging walls of mines," Fuel and Energy Abstracts, vol. 37, no. 4, p. 251, 1996.

[11] S. L. Sarkar and J. Wheeler, "Important properties of an ultrafine cement-part I," Cement and Concrete Research, vol. 31, no. 1, pp. 119-123, 2001.

[12] M. F. Gao, Q. L. Ma, Q. W. Lin, J. L. Chang, and H. Z. $\mathrm{Ma}$, "Fabrication and adsorption properties of hybrid fly ash composites," Applied Surface Science, vol. 396, pp. 400-411, 2017.

[13] J. Deng, Y. Xiao, J. Lu, H. Wen, and Y. Jin, "Application of composite fly ash gel to extinguish outcrop coal fires in China," Natural Hazards, vol. 79, no. 2, pp. 881-898, 2015.

[14] A. Kesimal, B. Ercikdi, and E. Yilmaz, "The effect of desliming by sedimentation on paste backfill performance," Minerals Engineering, vol. 16, no. 10, pp. 1009-1011, 2003.

[15] X. Yong-liang, W. De-ming, Z. Xiao-xing, T. Zhao-jun, and Q. $\mathrm{Xu}$-yao, "Study of inhibition characteristic of sand suspending 
thickener for spontaneous combustion prevention," in Proceedings of the 6th International Conference on Mining Science and Technology (ICMST '09), pp. 336-340, October 2009.

[16] B. T. Qin and Y. Lu, "Experimental research on inorganic solidified foam for sealing air leakage in coal mines," International Journal of Mining Science and Technology, vol. 23, no. 1, pp. 151155, 2013.

[17] M. S. Yun and W. I. Lee, "Analysis of bubble nucleation and growth in the pultrusion process of phenolic foam composites," Composites Science and Technology, vol. 68, no. 1, pp. 202-208, 2008.

[18] X. Ni and N. E. Pereira, "Parameters affecting fluid dispersion in a continuous oscillatory baffled tube," AIChE Journal, vol. 46, no. 1, pp. 37-45, 2000.

[19] C. B. Sudhish, Prevention and Combating Mine Fires, Crc Press, Rotterdam, Netherlands, 2000.

[20] G. J. Colaizzi, "Prevention, control and/or extinguishment of coal seam fires using cellular grout," International Journal of Coal Geology, vol. 59, no. 1-2, pp. 75-81, 2004.

[21] A. Sommer, Foaming Agent for Making Cellular Concrete and Method of Making Same, vol. 31, Hamburg-Wilhelsburg, Germany, 1964.

[22] E. K. K. Nambiar and K. Ramamurthy, "Influence of filler type on the properties of foam concrete," Cement and Concrete Composites, vol. 28, no. 5, pp. 475-480, 2006.

[23] E. P. Kearsley and P. J. Wainwright, "The effect of high fly ash content on the compressive strength of foamed concrete," Cement and Concrete Research, vol. 31, no. 1, pp. 105-112, 2001.

[24] E. P. Kearsley and P. J. Wainwright, "Porosity and permeability of foamed concrete," Cement and Concrete Research, vol. 31, no. 5, pp. 805-812, 2001.

[25] E. P. Kearsley and P. J. Wainwright, "The effect of porosity on the strength of foamed concrete," Cement and Concrete Research, vol. 32, no. 2, pp. 233-239, 2002.

[26] E. P. Kearsley and P. J. Wainwright, "Ash content for optimum strength of foamed concrete," Cement and Concrete Research, vol. 32, no. 2, pp. 241-246, 2002.

[27] J. Jambor, "Pore structure and strength development of cement composites," Cement and Concrete Research, vol. 20, no. 6, pp. 948-954, 1990.

[28] T. Luping, "A study of the quantitative relationship between strength and pore-size distribution of porous materials," Cement and Concrete Research, vol. 16, no. 1, pp. 87-96, 1986.

[29] E. K. K. Nambiar and K. Ramamurthy, "Air-void characterisation of foam concrete," Cement and Concrete Research, vol. 37, no. 2, pp. 221-230, 2007.

[30] B. T. Qin and D. M. Wang, "Present situation and development of mine fire control technology," China Safety Science Journal, vol. 12, no. 17, pp. 80-85, 2007.

[31] Z. J. Feng, B. T. Qin, J. H. Wang, and J. P. Zhang, "Application of three phase foam fire extinguishing technology in Xinji Mine," Coal Engineering, vol. 7, pp. 88-90, 2007.

[32] H. Zhao and J.-S. Liu, "The feasibility study of extinguishing oil tank fire by using compressed air foam system," in Proceedings of the 2015 7th International Conference on Performance-Based Fire and Fire Protection Engineering (ICPFFPE '16), vol. 135, pp. 61-66, December 2016.

[33] "JG/T266-2011, Foamed concrete, The construction industry standard of the People's Republic of China," 2011.

[34] M. R. Jones and A. McCarthy, "Utilising unprocessed low-lime coal fly ash in foamed concrete," Fuel, vol. 84, no. 11, pp. 13981409, 2005.
[35] G. M. Feng, Y. Ding, and H. J. Zhang, "Experimental research on a super high-water packing material for mining and its micromorphology," Journal of China University of Mining and Technology, vol. 39, no. 6, pp. 814-818, 2010.

[36] W. Zhao, Q. Zhu, and J. X. Zeng, "Fly ash-cement-based concrete performance test of the bubble," Sichuan Building Materials, vol. 36, no. 4, pp. 28-29, 2010.

[37] R. F. Feldman, G. G. Carette, and V. M. Malhotra, "Studies on mechanics of development of physical and mechanical properties of high-volume fly ash-cement pastes," Cement and Concrete Composites, vol. 12, no. 4, pp. 245-251, 1990.

[38] F. Cihangir, Investigation of utilisation of alkali activated blast furnace slag as binder in paste backfill [Ph.D. thesis], Karadeniz Technical University, Trabzon, Turkey, 2011.

[39] D. M. R. Stonr, “The optimization of mix designs for cemented rockfill," in Proceedings of the 5th Int. Symp. on Mining with Backfill Johannesburg (MINEFILL'93), pp. 249-253, SAIMM, 1993. 

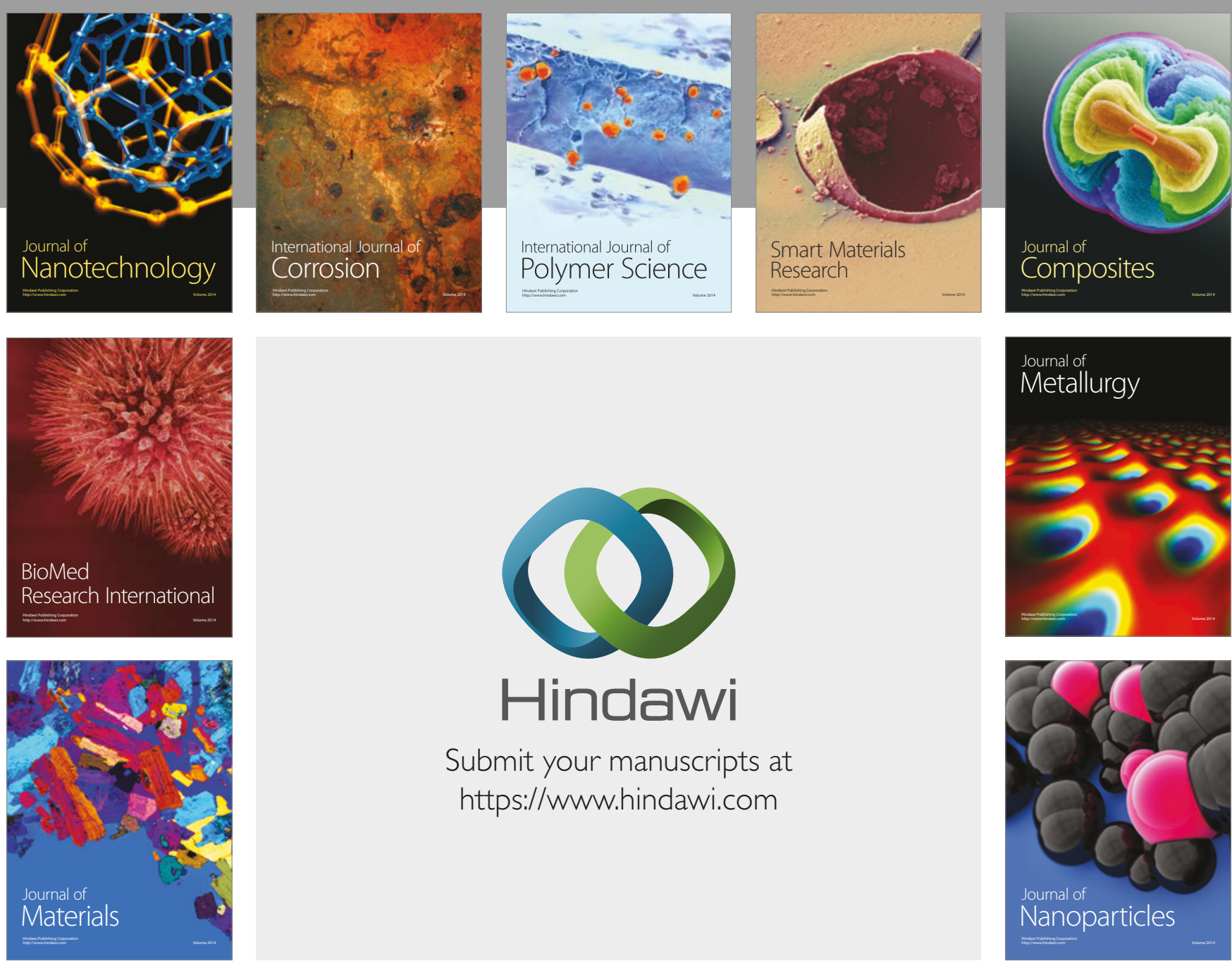

\section{Hindawi}

Submit your manuscripts at

https://www.hindawi.com
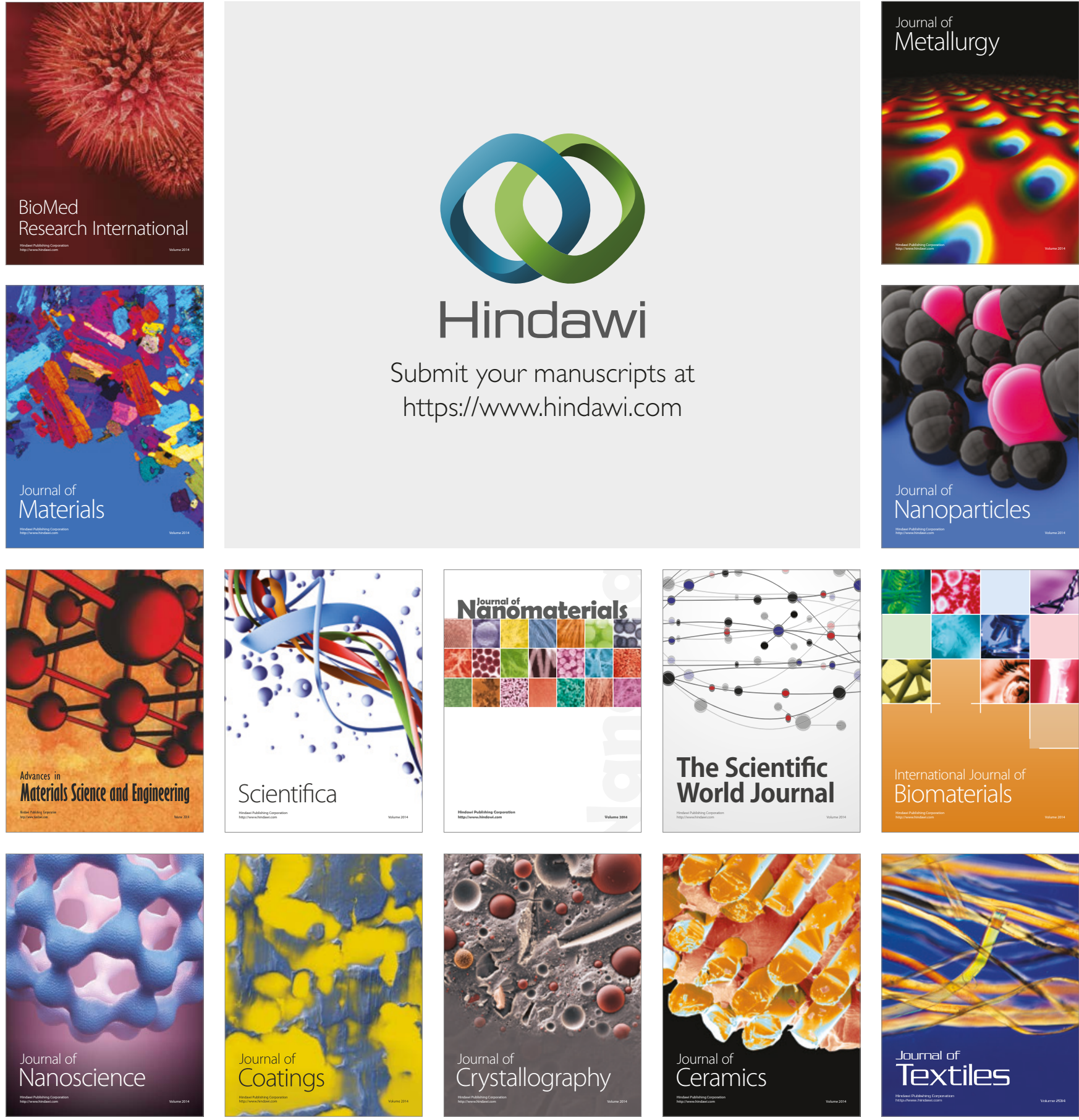

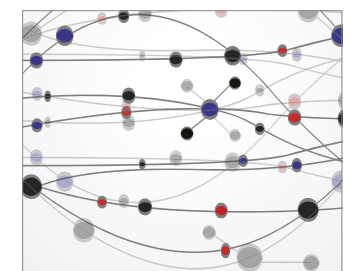

The Scientific World Journal
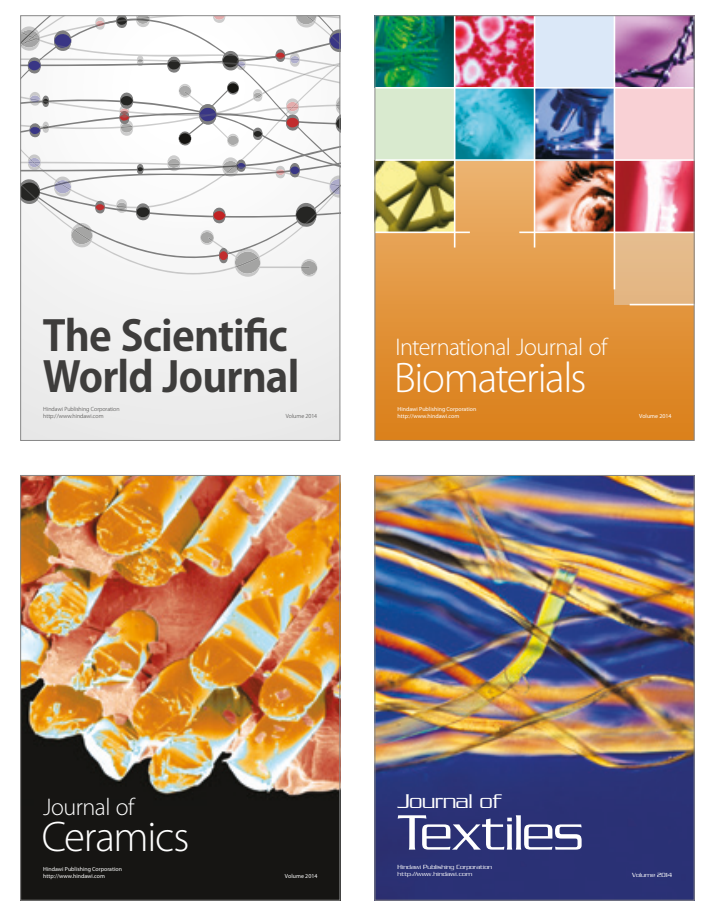